\title{
Effect of Counterion on the Solvatochromic Properties of Heteroleptic Chelate Copper(II) Complexes
}

\author{
Hamid Golchoubian and Hakimeh Fazilati \\ Department of Inorganic Chemistry, University of Mazandaran, Babolsar 47416-95447, Iran \\ Correspondence should be addressed to Hamid Golchoubian; h.golchobian@umz.ac.ir
}

Received 24 June 2012; Revised 26 July 2012; Accepted 4 August 2012

Academic Editor: K.S.V. Krishna Rao

Copyright (C) 2013 H. Golchoubian and H. Fazilati. This is an open access article distributed under the Creative Commons Attribution License, which permits unrestricted use, distribution, and reproduction in any medium, provided the original work is properly cited.

\begin{abstract}
A series of heteroleptic chelate copper(II) complexes of the type $[\mathrm{Cu}(\mathrm{L})(\mathrm{acac})] \mathrm{X}$ where acac $=$ acetylacetonate; $\mathrm{L}=\mathrm{N}, \mathrm{N}^{\prime}-1,6-\mathrm{bis}(2-$ fluorophenyl)-2,5-diazahexane; $\mathrm{X}=\mathrm{CIO}_{4}{ }^{-}, \mathrm{BPh}_{4}{ }^{-}, \mathrm{PF}_{6}{ }^{-}$, and $\mathrm{BF}_{4}^{-}$have been prepared and characterized by elemental analyses, IR and UV-Vis spectroscopies, and molar conductance measurements. The prepared complexes are fairly soluble in a large number of organic solvents and show positive solvatochromism. Among the complexes $[\mathrm{Cu}(\mathrm{L})(\mathrm{acac})] \mathrm{ClO}_{4}$, it is demonstrated the most solvatochromism. A multiparametric equation has been utilized to explain the solvent effect on the d-d transition of the complexes using SPSS/PC software. To explore the mechanism of interaction between solvent molecules and the complexes, different solvent parameters such as $\mathrm{DN}, \mathrm{AN}, \alpha, E_{T}(30), \pi^{*}$, and $\beta$ using stepwise multiple linear regression (SMLR) method were employed. The results demonstrated that the donor power of the solvent plays the most important role in the solvatochromism of the compounds.
\end{abstract}

\section{Introduction}

Solvatochromism behavior of inorganic complexes has been reviewed during the past four decades [1-3]. The phenomenon of solvatochromism which refers to changes in electronic absorption spectra with solvent is one of the important topics in solution chemistry. There exist a number of examples of solvatochromic metal complexes, and origins of the color changes are quite diverse. Solvatochromism of metal complexes can be divided into two types $[4,5]$, the first type comprises the case where the color changes are brought about by the direct attachment of solvent molecules onto metal center, and the second type is due to the attachment of solvent molecules onto ligands. Among the former whose color changes are due to those of $\mathrm{d}$ - $\mathrm{d}$ transitions, copper(II) complexes with a strong John-Teller effect can be anticipated to show simple and regular changes in their electronic spectra according to the strength of interactions with solvent molecules at the axial sites. This behavior in the heteroleptic chelate copper(II) complexes has received more interest because they may be used as a Lewis acid-base color indicator $[6,7]$ and also utilizes to develop optical sensor materials to monitor pollutant levels in the environment $[8,9]$. In this regard, extensive studies have been concentrated on the heteroleptic chelate complexes of copper(II) with acac and diamine derivatives (acac stands for acetylacetonate ion) [10-16].

Recently, we prepared a series of heteroleptic chelate copper(II) complexes that are soluble almost in a large number of solvents and show solvatochromic property [1826]. Our study demonstrated that the $\mathrm{ClO}_{4}^{-}$counterion is bound weakly above and below of the chelate plane in solution, and the perchlorate ions are driven out by solvent molecules leading to their solvatochromism $[27,28]$. In continuation of our study, we wish to report the syntheses and the solvatochromic behaviour of some of the heteroleptic chelate copper(II) complexes: shown in Figure 1, with different counterions $\mathrm{ClO}_{4}{ }^{-}, \mathrm{BPh}_{4}{ }^{-}, \mathrm{PF}_{6}{ }^{-}$, and $\mathrm{BF}_{4}{ }^{-}$in order to explore the role of the counter ions on the solvatochromism behavior and also to determine the relative donor power of these anions in the complexes.

\section{Materials and Methods}

The diamine compound and its heteroleptic chelate copper(II) complex with counterion of perchlorate was prepared according to published procedure [29]. All solvents were 


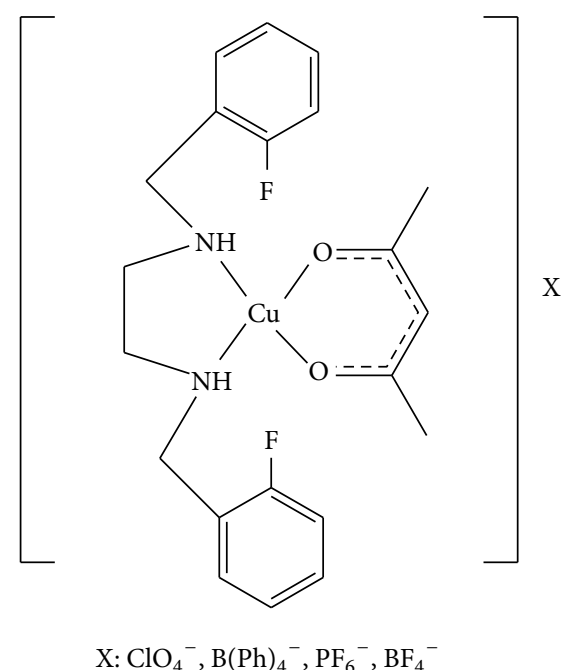

FIGURE 1: The complexes under study. the complexes. Multivariate statistical methods have been used in the classification and selection of solvents. The empirical parameters of the solvent polarity were used as basic data sets. These parameters can be obtained directly from the literature [30]. The extraction of the chemical information contained in such a data set can be carried out by statistical method of multiple linear regression analysis (MLR). Multiple linear regression of a dependent variable $Y_{s}$, with a series of explanatory variables $X_{1}, X_{2}, X_{3}$, and so forth., in (1) is a well-established model. The variable $Y_{s}$ is the solvent-dependent property ( $\nu_{\max }$ in this study) in a given solvent, $\mathrm{Y}_{0}$ is the statistical quantity representing the value of the property in the reference solvent (dichloromethane), $X_{1}, X_{2}, X_{3}$, and so forth. (explanatory variable) represent independent but complementary solvent parameters, which account for the solute-solvent interaction mechanism, and $a_{1}$, $a_{2}, a_{3}$, and so forth are the regression coefficients describing the sensitivity of property $Y_{s}$ to the different solute-solvent interaction mechanism. That is, suitable selection of bulk and molecular properties of solvents constitute linear or multiple regression analysis model equations

$$
Y_{s}=Y_{0}+a_{1} X_{1}+a_{2} X_{2}+a_{3} X_{3}+\cdots+a_{n} X_{n}
$$

All the samples were dried to constant weight under a high vacuum prior to analysis. Caution: perchlorate salts are potentially explosive and should be handled with appropriate care.

Conductance measurements were made at $25^{\circ} \mathrm{C}$ with a Jenway 400 conductance meter on $1.00 \times 10^{-3} \mathrm{M}$ samples. Infrared spectra (potassium bromide disk) were recorded using a Bruker FT-IR instrument. The electronic absorption spectra were measured using a Braic2100 model UVVis spectrophotometer. Elemental analyses were performed on a LECO $600 \mathrm{CHN}$ elemental analyzer. Absolute metal percentages were determined by a Varian-spectra A-30/40 atomic absorption-flame spectrometer.

\subsection{General Procedure for Preparation of Copper Complexes.} Tetraphenylborate complexes: the perchlorate mixed-chelate copper complexes $(1 \mathrm{mmol})$ were dissolved in methanol $(10 \mathrm{~mL})$ and heated (about $50^{\circ} \mathrm{C}$ ) until dissolution occurred. A saturated aqueous solution of sodium tetraphenylborate ( $4 \mathrm{mmol}$ ) in water was then added. The crystal precipitated out almost immediately. The reaction mixture was let to stand overnight and was then filtered (pore size 10-16 $\mu \mathrm{m}$ ), and the precipitate was washed with water several times. The yield was $65 \%$.

Hexafluorophosphate complexes: these complexes were prepared with the same procedure as tetraphenylborate complexes except that $\mathrm{NH}_{4} \mathrm{PF}_{6}$ was used instead of sodium tetraphenylborate. The yield was $43 \%$.

Tetrafluoroborate complexes: these complexes were prepared with the similar procedure as tetraphenylborate complexes except that $\mathrm{NH}_{4} \mathrm{BF}_{4}$ was used in place of sodium tetraphenylborate. The yield was $57 \%$.

2.2. Data analysis. All the absorption maxima reported were taken from experimental curves of the $d$-d transition of
The solvent properties investigated are Dimroth and Reichardt's $E_{T}(30)$, Kamlet and Taft's $\alpha, \beta, \pi^{*}$, Gutmann's donor $\mathrm{DN}$, and acceptor number AN.

In this paper, stepwise multiple linear regression (SMLR) method was used to generate the best models of the solvent parameters using SPSS/PC software package [31]. The stepwise method involves three main steps: (1) identifying an initial model, (2) changing the model at the previous step by adding or removing a parameter, and (3) obtaining the best model when stepping is no longer possible and all the parameters reviewed and evaluated to specify which one contributes the most to the equation in [32]. The variance of the data in this procedure plays a main role so that when a new parameter is entered into the equation, its value changes. When the importance of a parameter with entering new data decreases the stepwise method removes the weakened parameter. This procedure continues till a final equation is obtained. The final equation is also tested for stability and validity of the results by the computer program itself. The appropriate equation is selected by considering four criteria, namely, multiple correlation coefficients $(R)$, standard error (SE), F-statistic, and the number of parameters in the model $(N)$. The best model is the one with higher $R$ and $F$-values, lower standard error, the least number of parameters and high ability for prediction [33]. In parameter selection, variables with small variance $t$ (not significant at the $5 \%$ level) were then removed. " $t$ " value is the solventindependent coefficients divided by SE.

The following solvents were used for solvatochromic study: dichloromethane (DCM), nitromethane (NM), acetonitrile $(\mathrm{AN})$, acetone $(\mathrm{Ac})$, tetrahydrofuran (THF), methanol (MeOH), dimethylformamide (DMF), dimethylsulfoxide (DMSO), and pyridine (Py). 


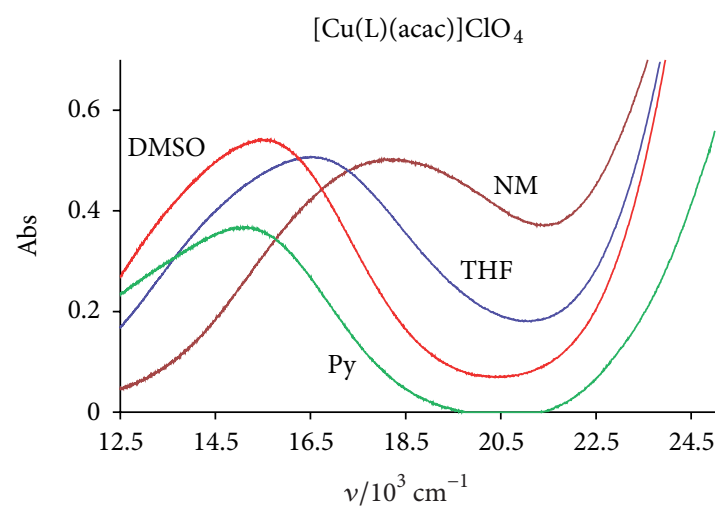

(a)

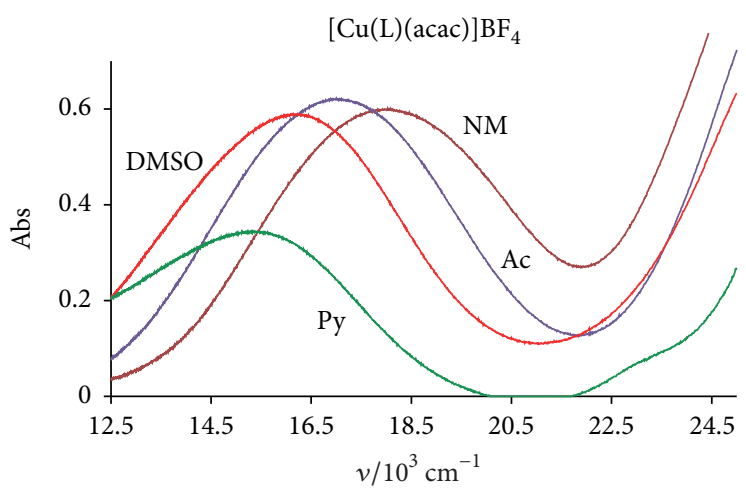

(c)

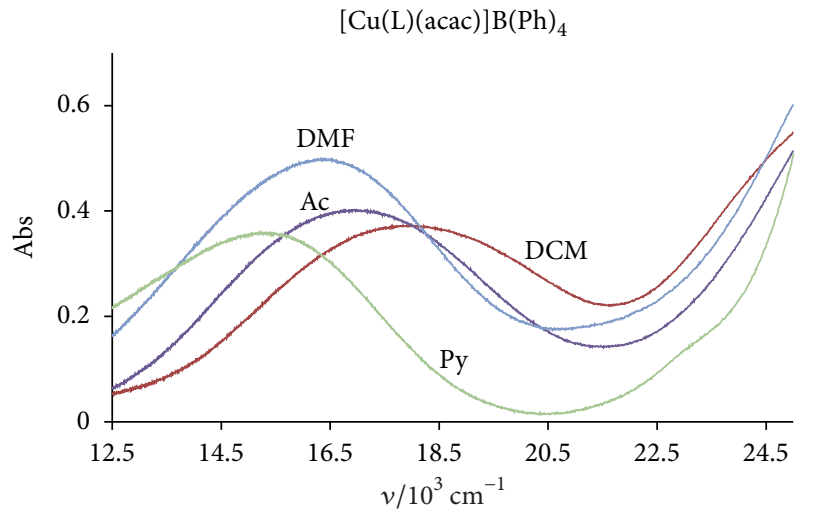

(b)

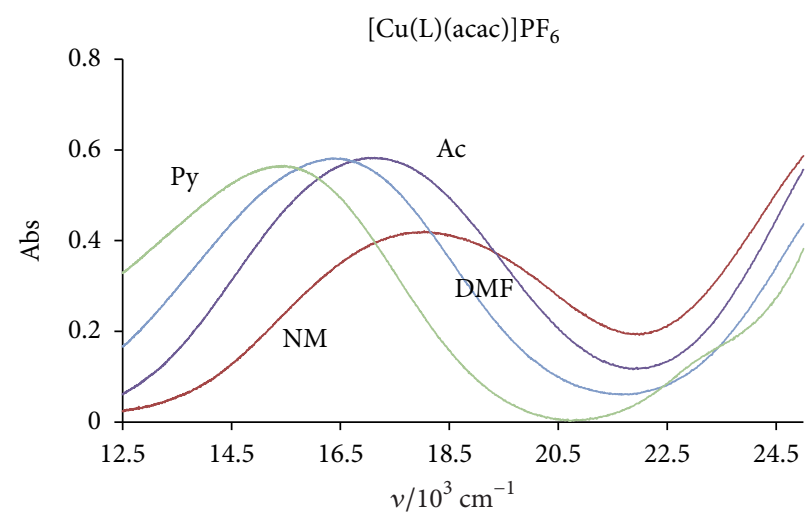

(d)

Figure 2: Absorption spectra of the complexes in selected solvents. Absorption spectra in other solvents are omitted for clarity.

TABLE 1: Color, yields, and analytical data of the complexes obtained.

\begin{tabular}{|c|c|c|c|c|c|}
\hline \multirow{2}{*}{ Complex number } & \multirow{2}{*}{ Complex (color/yield) } & \multicolumn{4}{|c|}{ Analysis; found (calcd) } \\
\hline & & $\mathrm{C} \%$ & $\mathrm{H} \%$ & N\% & $\mathrm{Cu} \%$ \\
\hline \multirow{2}{*}{1} & {$[\mathrm{Cu}(\mathrm{L})(\mathrm{acac})] \mathrm{ClO}_{4}$} & 46.71 & 4.88 & 5.14 & 11.68 \\
\hline & (bluish violet/74\%) & $(46.84)$ & $(4.68)$ & $(5.20)$ & $(11.80)$ \\
\hline \multirow{2}{*}{2} & {$[\mathrm{Cu}(\mathrm{L})(\mathrm{acac})] \mathrm{B}(\mathrm{Ph})_{4}$} & 71.10 & 6.23 & 3.68 & 8.36 \\
\hline & (Purple/65\%) & $(71.28)$ & $(5.98)$ & $(3.69)$ & $(8.38)$ \\
\hline \multirow{2}{*}{3} & {$[\mathrm{Cu}(\mathrm{L})(\mathrm{acac})] \mathrm{PF}_{6}$} & 43.33 & 4.20 & 4.58 & 10.82 \\
\hline & (Purple/43\%) & $(43.19)$ & $(4.32)$ & $(4.80)$ & $(10.88)$ \\
\hline \multirow{2}{*}{4} & {$[\mathrm{Cu}(\mathrm{L})(\mathrm{acac})] \mathrm{BF}_{4}$} & 48.19 & 4.47 & 5.01 & 11.99 \\
\hline & (Deep blue/57\%) & $(47.97)$ & $(4.79)$ & $(5.33)$ & (12.09) \\
\hline
\end{tabular}

TABle 2: Molar conductivities data $\left(\Lambda_{m}\right)$ of the complexes $\left(\Omega^{-1} \mathrm{~cm}^{2} \mathrm{~mol}^{-1} \text {, at } 25^{\circ} \mathrm{C}\right)^{\mathrm{a}}$ in different solvents.

\begin{tabular}{lccccc}
\hline Complex & $\mathrm{CH}_{2} \mathrm{Cl}_{2}$ & $\mathrm{CH}_{3} \mathrm{CN}$ & EtOH & Acetone & DMF \\
\hline$[\mathrm{Cu}(\mathrm{L})(\mathrm{acac})] \mathrm{ClO}_{4}$ & 6 & 136 & 48 & 129 & 96 \\
{$[\mathrm{Cu}(\mathrm{L})(\mathrm{acac})] \mathrm{B}(\mathrm{Ph})_{4}$} & 7 & 144 & 25 & 46 & 133 \\
{$[\mathrm{Cu}(\mathrm{L})(\mathrm{acac})] \mathrm{PF}_{6}$} & 3 & 151 & 35 & 141 & 68 \\
{$[\mathrm{Cu}(\mathrm{L})(\mathrm{acac})] \mathrm{BF}_{4}$} & 7 & 126 & $35-45$ & $100-140$ \\
$1: 1$ electrolytes & $10-20$ & $120-160$ & $65-90$ \\
\hline
\end{tabular}

Concentration: $c a .1 \times 10^{-3} \mathrm{M}$.

$\mathrm{b}$ data for standard values taken from [17]. 
TABLE 3: Electronic absorption maxima of the complexes in various solvents: $v_{\max } / 10^{3} \mathrm{~cm}^{-1}\left(\varepsilon / \mathrm{M}^{-1} \mathrm{~cm}^{-1}\right)$.

\begin{tabular}{lcccc}
\hline Solvent & Complex 1 & Complex 2 & Complex 3 & Complex 4 \\
\hline DCM & $17.33(81)$ & $16.64(69)$ & $17.51(71)$ & $17.64(104)$ \\
NM & $18.05(100)$ & $17.95(107)$ & $18.05(89)$ & $17.04(78)$ \\
AN & $16.81(88)$ & $16.98(93)$ & $17.08(120)$ & $17.01(100)$ \\
Ac & $17.12(95)$ & $16.95(80)$ & $16.89(90)$ & $17.01(124)$ \\
THF & $16.50(101)$ & $16.75(116)$ & $16.86(110)$ & $16.89(94)$ \\
MeOH & $16.75(51)$ & $16.81(80)$ & $16.37(116)$ & $16.84(118)$ \\
DMF & $16.42(143)$ & $16.34(99)$ & $16.18(113)$ & $16.26(111)$ \\
DMSO & $15.48(108)$ & $16.10(69)$ & $15.48(113)$ & $16.10(117)$ \\
Py & $15.15(69)$ & $15.38(75)$ & & $15.34(69)$ \\
\hline
\end{tabular}

TABLE 4: The solvent parameter values.

\begin{tabular}{lcccccc}
\hline Solvent & DN & AN & $E_{T}(30)$ & $\beta$ & $\alpha$ & $\pi^{*}$ \\
\hline DCM & 0.0 & 20.4 & 40.7 & 0.10 & 0.13 & 0.82 \\
NM & 2.7 & 20.5 & 46.3 & 0.06 & 0.22 & 0.85 \\
AN & 14.1 & 18.9 & 45.6 & 0.40 & 0.19 & 0.75 \\
Ac & 17.0 & 12.5 & 42.2 & 0.43 & 0.08 & 0.71 \\
THF & 20.0 & 8.0 & 37.4 & 0.55 & 0.00 & 0.58 \\
MeOH & 19.0 & 41.3 & 55.4 & 0.66 & 0.98 & 0.60 \\
DMF & 26.6 & 16.0 & 43.8 & 0.69 & 0.00 & 0.88 \\
DMSO & 29.8 & 19.3 & 45.1 & 0.76 & 0.00 & 1.00 \\
Py & 33.1 & 14.2 & 40.5 & 0.64 & 0.00 & 0.87 \\
\hline
\end{tabular}

\section{Results and Discussion}

The compositions of chelates obtained as fine crystalline powders can be confirmed with the general formula, $[\mathrm{Cu}(\mathrm{L})(\mathrm{acac})] \mathrm{X}$, where acac stands for acetylacetonate ion, $\mathrm{L}$ is as $\mathrm{N}, \mathrm{N}^{\prime}$-1,6-bis(2-fluorophenyl)-2,5-diazahexane, and $\mathrm{X}$ is a univalent anion such as $\mathrm{ClO}_{4}{ }^{-}, \mathrm{B}(\mathrm{Ph})_{4}{ }^{-}, \mathrm{PF}_{6}{ }^{-}$, and $\mathrm{BF}_{4}{ }^{-}$. The results of elemental analysis and color of the complexes are shown in Table 1.

3.1. Infrared Spectra. Formation of the heteroleptic chelate copper (II) complexes can be concluded from IR spectroscopy. The similarity among the infrared spectra of the complexes might imply that the structures of all complexes are the same, and the only differences are due to presence of different counter ions. Two intense absorption bands in the region around $1520 \mathrm{~cm}^{-1}$ in the complexes could be assigned to the $\mathrm{C}=\mathrm{C}$ and $\mathrm{C}=\mathrm{O}$ vibrational modes [34]. A vibrational band around $945 \mathrm{~cm}^{-1}$ observed in all complexes is associated to $\mathrm{C}-\mathrm{F}$ stretching of the diamine chelate. The $\mathrm{N}-\mathrm{H}$ stretching vibration of the diamine ligand appears in the $3200-3240 \mathrm{~cm}^{-1}$ region. The vibrational bands around $1040 \mathrm{~cm}^{-1}$ corresponded to the stretching vibration of $\mathrm{C}-\mathrm{N}$ bond, and the bands around $1450 \mathrm{~cm}^{-1}$ are associated to the scissoring vibration of $-\mathrm{CH}_{2}-$ groups [35]. Dependence on substitution of $\mathrm{ClO}_{4}{ }^{-}$by $\mathrm{B}(\mathrm{Ph})_{4}{ }^{-}$can be verified by disappearance of perchlorate bands at around 1097 and 638 $\mathrm{cm}^{-1}$ and appearance of the intense absorptions bands at 770, 740,1510 , and $1595 \mathrm{~cm}^{-1}$ which are corresponded to the phenyl group of tetraphenylborate ion [36]. Although the first two absorption bands are clearly perceived, the positioning of the vibrations of the acac group does not enable us to observe the last two absorptions in complex 2. The existence of $\mathrm{PF}_{6}{ }^{-}$ ion is exhibited by intense and medium bands occurring at 640 and $560 \mathrm{~cm}^{-1}$, respectively, which confirms the formation of complex 3 [37]. The presence of $\mathrm{BF}_{4}{ }^{-}$group is declared by two intense bands at around $1090 \mathrm{~cm}^{-1}$ and $1400 \mathrm{~cm}^{-1}$ which are attributed to the antisymmetric stretching and antisymmetric bending vibration modes, respectively [33]. The former band is split with a poorly defined maximum showing deformation from $\mathrm{T}_{d}$ symmetry.

3.2. Conductometric Data. Table 2 illustrates the molar conductivity values of complexes in different solvents. The standard values of $1: 1$ electrolytes in the respective solvents are illustrated in the same table [17]. The results show that in solvent of dichloromethane the values are much lower than that for $1: 1$ electrolyte when $\mathrm{X}$ is $\mathrm{PF}_{6}{ }^{-}, \mathrm{BF}_{4}{ }^{-}$, and $\mathrm{ClO}_{4}{ }^{-}$. However, in other solvents, all of the complexes are 1:1 electrolyte which indicates almost complete dissociation into $\mathrm{X}^{-}$and the cationic complexes $[\mathrm{Cu}(\mathrm{L})(\mathrm{acac})]^{+}$. Thus, it seems that an ion-pair formation (or anion coordination) might exist in some extent in $\mathrm{CH}_{2} \mathrm{Cl}_{2}$. This means that these ions are bound weakly above and below of the chelate planes and can be driven out by high donor power solvent molecules which leading to their solvatochromism. These results are in general agreement with the expectation from the spectral data and with our pervious results [29]. However, the complexes of $[\mathrm{Cu}(\mathrm{L})(\mathrm{acac})] \mathrm{B}(\mathrm{Ph})_{4}$ almost completely dissociate in nonpolar solvent. As a result, in contrast with other counteranions, there is not any bond between copper ion and anion of $\mathrm{B}(\mathrm{Ph})_{4}{ }^{-}$. In case of $[\mathrm{Cu}(\mathrm{L})(\mathrm{acac})] \mathrm{B}(\mathrm{Ph})_{4}$, the conductance values are lower than the expected values due to low mobility of bulky anion of tetraphenylborate in the solution [17].

3.3. Solvatochromism. All the complexes are easily soluble in a wide range of organic solvents. The presence of a strong John-Teller effect on the $\mathrm{Cu}$ (II) ions made them good solvatochromic probes. The electronic absorption spectra of the complexes are characterized by a broad structureless band in the visible region attributed to the promotion of an electron 
TABLE 5: Selected models of SMLR method and related values of $F, R$, SE, and $\Delta v_{\max } \mathrm{cm}^{-1}$.

\begin{tabular}{llcccc}
\hline Complexes & Equations & $F$ & $R$ & $\mathrm{SE}$ & $\Delta v_{\max } / \mathrm{cm}^{-1}$ \\
\hline 1 & $v_{\max }=-0.072( \pm 0.012) \mathrm{DN}_{\text {solv }}+17.920( \pm 0.259)$ & 33.803 & 0.910 & 0.400 & 2900 \\
2 & $v_{\max }=-0.076( \pm 0.007) \mathrm{DN}_{\text {solv }}+18.193( \pm 0.149)$ & 126.618 & 0.977 & 0.172 & 2570 \\
3 & $v_{\max }=-0.063( \pm 0.008) \mathrm{DN}_{\text {solv }}+17.953( \pm 0.177)$ & 54.874 & 0.942 & 0.270 & 2570 \\
4 & $v_{\max }=-0.069( \pm 0.008) \mathrm{DN}_{\text {solv }}+18.040( \pm 0.175)$ & 68.598 & 0.953 & 0.266 & 2740 \\
\hline
\end{tabular}

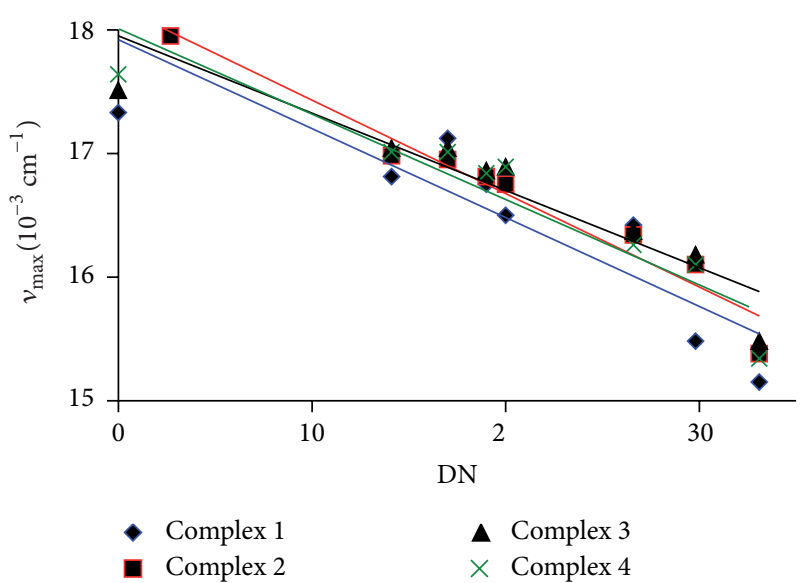

FIGURE 3: Dependence of the $v_{\max }$ values of complexes 1-4 on the solvent $\mathrm{DN}$ values.

in the low-energy orbitals to the hole in $d_{x^{2}-y^{2}}$ orbital of the copper(II) ion $\left(\mathrm{d}^{9}\right)$. The visible spectral changes of these complexes in the selected solvents are illustrated in Figure 2. The positions of the $v_{\max }$ values of the complexes along with the molar absorptivities are collected in Table 3. All of the complexes show the solvatochromic behavior, and the shifts induced in certain solvents depend upon the nature of the counter ions.

To explore the solvent effects on the absorption spectra of the complexes, the absorption frequencies $\left(v_{\max }\right)$ were correlated with the solvatochromic (1). Hence, the frequencies of $\mathrm{d}$ - $\mathrm{d}$ absorption transition band $\left(v_{\max }\right)$ of each complexes in various solvents with their own solvent parameters shown in Table 4 were offered in Equation (2) one by one to the statistical computer program, being accepted, rejected, or exchanged until certain statistical criteria are met.

The solvent parameters used include Gutmann's donor number [30], DN (donor number is a measure of coordinating ability of solvents on the standard of dichloromethane), Mayer and Gutmann's acceptor number, AN (the electron acceptor property of a solvent), Dimroth and Reichardt's $E_{T}(30)$ (a measure of the ionization power of a solvent), Kamlet and Taft's $\alpha$ (hydrogen bond donation of the solvent), $\beta$ (hydrogen bond acceptance of solvent) and $\pi *$ (polarity/polarisability parameter of solvent):

$$
\begin{aligned}
v_{\max }= & v_{\text {max }}^{o}+a \mathrm{DN}+b \mathrm{AN}+c \beta+d \alpha+e \pi^{*} \\
& +f E_{T}(30) .
\end{aligned}
$$

The results obtained from the correlation of the absorption frequencies with the solvent parameters are illustrated in Table 5. The data in Table 5 show that dominate solvent effect in all complexes is DN and contribution of the other solvent parameters was rejected based on the statistical criteria explained in the experimental section.

According to the results obtained, the DN parameter of the solvent has a dominate contribution in (2) for compounds 1-4 and governs the shift of the d-d absorption band of the complexes. The negative sign of the coefficient $a$ indicates a red shift as the donor number of solvents increases. The red shift observed in the $\mathrm{d}$-d visible absorption band originates in variation of Lewis acid-base interaction between the chelates around the copper ions and the respective solvents molecules. Hence, approaching of the polar solvent molecules to the axial position of the complexes causes a strong repulsion between the electron in the $d z^{2}$ orbital of the copper(II) ions and the electron pair of the solvents and as a result of decreasing the required energy for transferring the electrons to $d_{x^{2}-y^{2}}$ orbital. Accordingly, the position of this band decreases nearly linearly with the increasing of the donor numbers of the solvents. The plots of the observed $v_{\max }$ values of the complexes versus the donor number of the solvents as shown in Figure 3 demonstrated good correlation for all complexes.

The relative donor power of the anions can be investigated in low donor number solvents such as dichloromethane and nitromethane. As evident from Table 3 the relative donor power of anions $\mathrm{X}$ is in the following order:

$$
\mathrm{BF}_{4}^{-}>\mathrm{PF}_{6}^{-}>\mathrm{ClO}_{4}^{-}>\mathrm{B}(\mathrm{Ph})_{4}^{-}
$$

\section{Conclusion}

Solvatochromic heteroleptic chelate copper(II) complexes with different counterion were prepared. The properties of the solvatochromic complexes [ $\mathrm{Cu}(\mathrm{L})(\mathrm{acac})$ (diamine)]X $\left(\mathrm{X}=\mathrm{ClO}_{4}^{-}, \mathrm{B}(\mathrm{Ph})_{4}^{-}, \mathrm{PF}_{6}^{-}\right.$, and $\left.\mathrm{BF}_{4}^{-}\right)$were studied in solution. Their solvatochromism behaviors were examined with different solvent parameters using SMLR computational method. The statistical evaluation of the data $(R, S$. E. and $F$-test) indicated that the DN parameter of the solvent plays the most important role in the solvatochromic behavior of the complexes. It was understood that the solvatochromic behavior of the complexes depends upon two main factors, the coordination ability of solvents and counter ions. All the complexes demonstrated positive solvatochromism, as the $\mathrm{DN}$ of the solvent increases with increasing donor number of solvent. In solvation procedure, the geometry of the complexes changes from square planar to octahedral. Among 
the complexes studied, complex $\mathbf{1}\left(\mathrm{X}=\mathrm{ClO}_{4}{ }^{-}\right)$showed the highest $\Delta v_{\max }$ value.

\section{Acknowledgment}

The authors are grateful for the financial support of the University of Mazandaran, Iran.

\section{References}

[1] W. Linert, Y. Fukuda, and A. Camard, "Chromotropism of coordination compounds and its applications in solution," Coordination Chemistry Reviews, vol. 218, pp. 113-152, 2001.

[2] K. Sone and Y. Fukuda, Inorganic Thermochromism (Inorganic Chemistry Concepts), Springer, Berlin, Germany, 1987.

[3] Y. Fukuda, M. Yasuhira, and K. Sone, "Studies on mixed chelates. XIV. influences of solvent polarity, and of substituent groups in $\beta$-diketonate ligands, on the electronic spectra of 5 coordinated mixed copper(II) chelates in organic solutions," Bulletin of the Chemical Society of Japan, vol. 58, pp. 3518-3523, 1985.

[4] K. Sone and Y. Fukuda, "Organic ligands in donor and acceptor solvents," Reviews in Inorganic Chemistry, vol. 11, pp. 123-153, 1990.

[5] W. Linert, R. F. Jameson, and A. Taha, "Donor numbers of anions in solution: the use of solvatochromic Lewis acid-base indicators," Journal of the Chemical Society, Dalton Transactions, no. 21, pp. 3181-3186, 1993.

[6] K. Sone, Y. Fukuda, H. Tanaka, H. Ohtaki, and R. Tamamushi, in Ions and Molecules in Solution, p. 251, Elsevier, Amsterdam, The Netherlands, 1983.

[7] K. Miyamoto, M. Sakamoto, C. Tanaka, E. Horn, and Y. Fukuda, "Syntheses, structures, spectroscopic properties, and thermal behavior of nickel(II) mixed-ligand complexes with $\mathrm{N}, \mathrm{N}, \mathrm{N}^{\prime}, \mathrm{N}^{\prime}$ tetramethylethylenediamine, benzoylacetonate, and a halide anion," Bulletin of the Chemical Society of Japan, vol. 78, no. 6, pp. 1061-1071, 2005.

[8] K. Sone and Y. Fukuda, "Inorganic thermochromism," in Inorganic Chemistry Concepts, Springer, Berlin, Germany, 1987.

[9] J. L. Meinershagen and T. Bein, "Solvatochromism of a copper(II) (tetramethylethylenediamine)-(acetylacetonate)+ complex encapsulated in EMT zeolite cages," Advanced Materials, vol. 13, no. 3, pp. 208-211, 2001.

[10] Y. Fukuda, Y. Miura, and K. Sone, "Studies on mixed chelates. VI. mixed copper(II) chelates with N,N,N'N'-tetraethylethylenediamine and various $\beta$-diketones," Bulletin of the Chemical Society of Japan, vol. 50, pp. 142-144, 1977.

[11] R. W. Soukup and K. Sone, "(Acetylacetonato)(N,N,N,N'tetramethylethylenediamine) copper(II) tetraphenylborate as a solvent basicity indicator," Bulletin of the Chemical Society of Japan, vol. 60, pp. 2286-2288, 1987.

[12] J. Labuda, K. Mafune, and Y. Fukuda, "Effect of solvent on the electrochemical properties of chromotropic copper(II) mixed chelates," Bulletin of the Chemical Society of Japan, vol. 63, pp. 2610-2614, 1990.

[13] Y. Fukuda, N. Sato, N. Hoshio, and K. Sone, "Studies on mixed chelates. XII. Formation and electronic spectra of 5coordinated mixed copper(II) chelates containing $\mathrm{N}$-alkylated ethylenediamine, acetylacetonate and pseudohalide anions," Bulletin of the Chemical Society of Japan, vol. 54, pp. 428-432, 1981.
[14] S. I. Noro, N. Yanai, S. Kitagawa, T. Akutagawa, and T. Nakamura, "Binding properties of solvatochromic indicators $[\mathrm{Cu}(\mathrm{X})(\mathrm{acac})(\mathrm{tmen})]\left(\mathrm{X}=\mathrm{PF}_{6}^{-}\right.$and $\mathrm{BF}_{4}^{-}$, acac- = acetylacetonate, tmen $=\mathrm{N}, \mathrm{N}, \mathrm{N}^{\prime}, \mathrm{N}^{\prime}$-tetramethylethylenediamine) in solution and the solid state," Inorganic Chemistry, vol. 47, no. 16, pp. 7360-7365, 2008.

[15] Y. Fukuda, H. Kimura, and K. Sone, "Studies on mixed chelates. XIII. Formation and electronic spectra of 5-coordinated mixed copper(II) chelates containing $\mathrm{N}$-alkylated ethylenediamine, acetylacetonate, and halide anions," Bulletin of the Chemical Society of Japan, vol. 55, pp. 3738-3741, 1982.

[16] M. Afzaal, E. Flynn, M. A. Malik, P. O’Brien, and M. Motevalli, "Mixed ligand chelates of copper(II) with substituted diamines," Polyhedron, vol. 24, no. 9, pp. 1101-1107, 2005.

[17] W. J. Geary, "The use of conductivity measurements in organic solvents for the characterisation of coordination compounds," Coordination Chemistry Reviews, vol. 7, no. 1, pp. 81-122, 1971.

[18] H. Golchoubian, Z. Mohseni Afshar, G. Moayyedi, G. Bruno, and H. Amiri Rudbari, "Synthesis, characterization and solvatochromism investigation of mixed ligand chelate copper(II) complexes with acetyleacetonate and three diamine ligands," Chinese Journal of Chemistry, vol. 30, no. 8, pp. 1873-1880, 2012.

[19] H. Golchoubian and F. Khoshsiar, "Substituent effect in the $\gamma$-position of acetylacetonate on the solvatochromic property of bis(acetylacetonato)copper(II) complexes," Chemistry Journal, vol. 2, pp. 36-43, 2012.

[20] H. Golchoubian, G. Moayyedi, G. Bruno, and H. A. Rudbari, "Syntheses and characterization of mixed-chelate copper(II) complexes containing different counter ions; spectroscopic studies on solvatochromic properties," Polyhedron, vol. 30, no. 6, pp. 1027-1034, 2011.

[21] H. Golchoubian, O. Nazari, and B. Kariuki, "Synthesis, structure and solvatochromism studies on copper(II) complexes containing ethylenediamine, pyridine and imidazol ligands," Journal of the Chinese Chemical Society, vol. 58, no. 1, pp. 60-68, 2011.

[22] H. Golchoubian, E. Rezaee, G. Bruno, and H. A. Rudbari, "Synthesis and solvatochromism studies of new mixed-chelate dinuclear copper(II) complexes with different counter ions," Inorganica Chimica Acta, vol. 366, no. 1, pp. 290-297, 2011.

[23] H. Golchoubian and R. Z. Zarabi, "Syntheses, crystal structure and chromotropic properties of dinuclear copper(II) complexes of tertiary diamine with hydroxo bridge," Polyhedron, vol. 28, no. 17, pp. 3685-3690, 2009.

[24] H. Golchoubian and E. Rezaee, "Substituent effect in the $\gamma$ position of acetylacetonate on the solvatochromic property of mixed-chelate copper(II) complexes consisting of diamine and acetylacetonate ligands," Journal of Molecular Structure, vol. 929, no. 1-3, pp. 154-158, 2009.

[25] H. Golchoubian and E. Rezaee, "Chromotropism of a new mixed-chelate copper(II) complex," Journal of Molecular Structure, vol. 927, no. 1-3, pp. 91-95, 2009.

[26] E. Movahedi and H. Golchoubian, "Substituent and solvent effects in the spectra of new mixed-chelate copper (II) complexes containing N,N/-disubstituted ethylenediimine and acetylacetonate ligands," Journal of Molecular Structure, vol. 787, no. 1-3, pp. 167-171, 2006.

[27] H. Golchoubian, G. Moayyedi, and H. Fazilati, "Spectroscopic studies on solvatochromic of mixed-chelate copper(II) complexes using MLR technique," Spectrochimica Acta A, vol. 85, pp. 25-30, 2012. 
[28] H. Golchoubian, "Crystal structure of a new mixed-chelate complex of $[\mathrm{Cu}$ (diamine)(acac) $] \mathrm{ClO}_{4}$," Analytical Sciences, vol. 24, no. 8, pp. x169-x170, 2008.

[29] H. Asadi, H. Golchoubia, and R. Welter, "Synthesis, structural and solvent influence studies on solvatochromic of acetylacetonatocopper(II) with $\mathrm{N}, \mathrm{N}^{\prime}$-dibenzylic or thiophene derivatives of ethylenediamine complexes," Journal of Molecular Structure, vol. 779, no. 1-3, pp. 30-37, 2005.

[30] V. Gutmann, Coordination Chemistry in Non-Aqueous Solutions, Springer, Vienna, Austria, 1968.

[31] SPSS/PS, Statistical package for IBMPC, Quiad software version 13, Ontario, 1998.

[32] R. B. Darlington, Regression and Linear Models, McGraw-Hill, New York, NY, USA, 1990.

[33] S. Riahi, M. F. Mousavi, and M. Shamsipur, "Prediction of selectivity coefficients of a theophylline-selective electrode using MLR and ANN," Talanta, vol. 69, no. 3, pp. 736-740, 2006.

[34] K. Nakamoto, in Infrared and Raman Spectra of Inorganic and Coordination Compounds, Wiley-Interscience, New York, NY, USA, 4th edition, 1986.

[35] C. Tsiamis and M. Themeli, "Substituent and solvent effects in the spectra and structure of some mixed-ligand copper(II) chelates containing $\beta$-ketoenols," Inorganica Chimica Acta, vol. 206, no. 1, pp. 105-115, 1993.

[36] N. Sekine, T. Shiga, M. Ohba, and H. Okawa, "Dinuclear copper(II) complexes of a macrocyclic compartmental ligand in two isomeric forms. exogenous ion effect upon ligand isomerism," Bulletin of the Chemical Society of Japan, vol. 79, no. 6, pp. 881-885, 2006.

[37] D. Dolphin and A. Wick, Tabulation of Infrared Spectral Data, Wiley-Interscience, New York, NY, USA, 1977. 

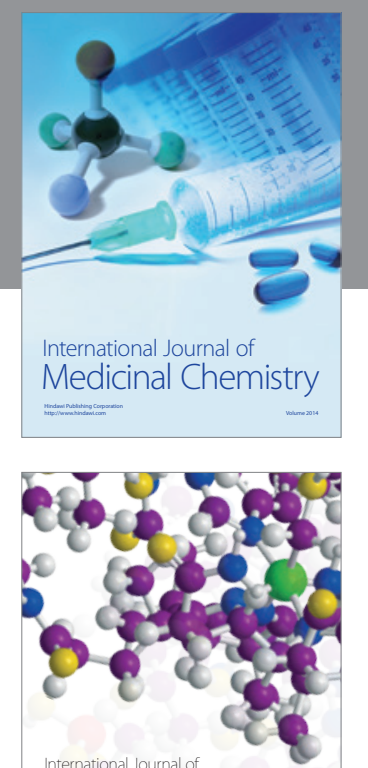

\section{Carbohydrate} Chemistry

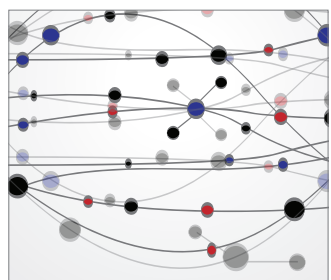

The Scientific World Journal
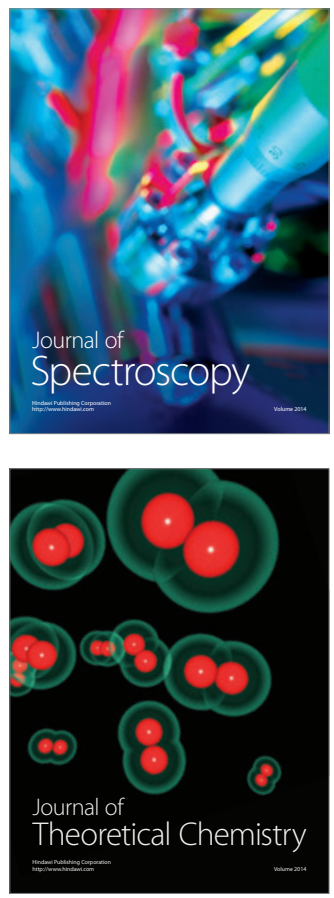
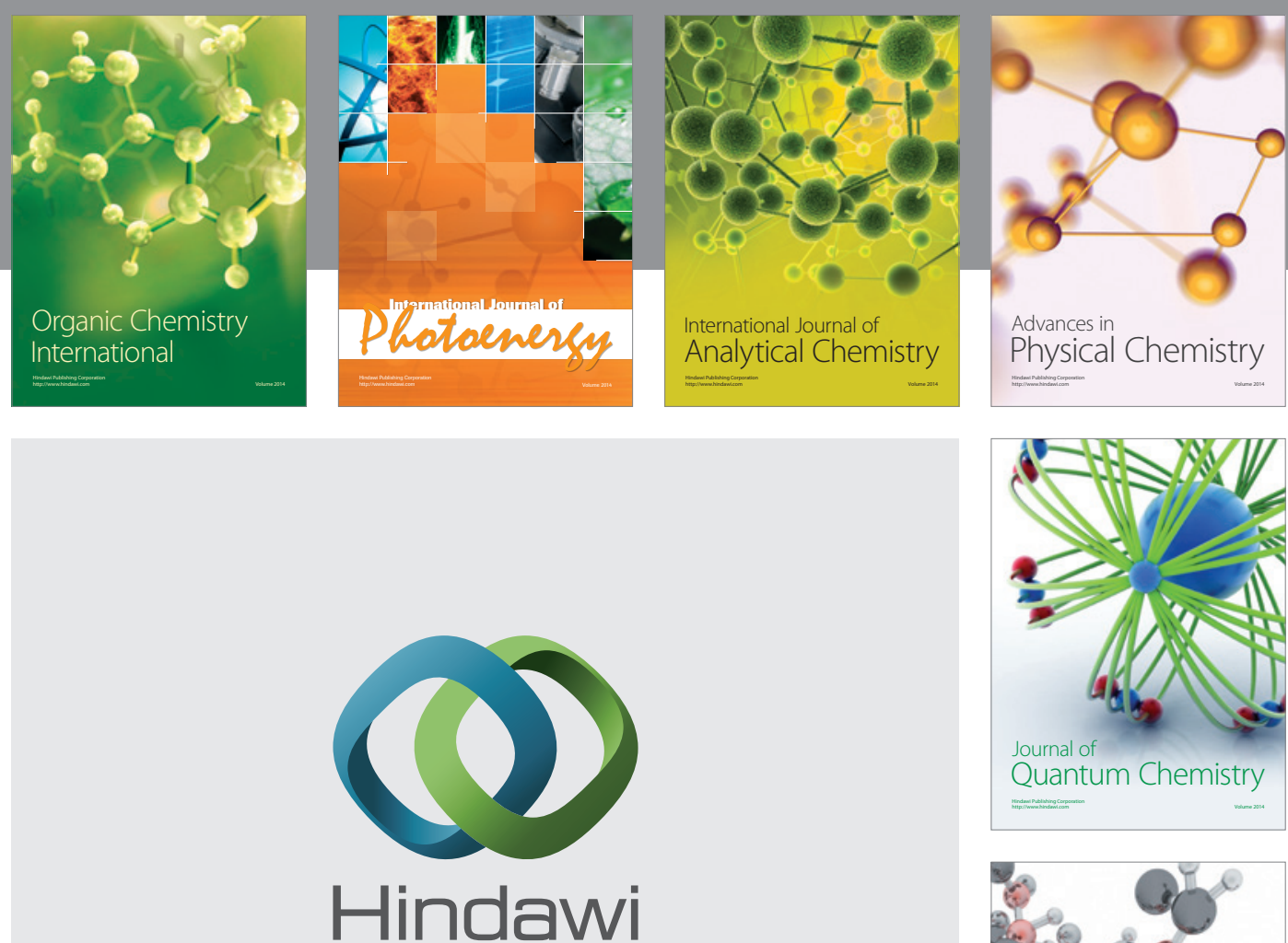

Submit your manuscripts at

http://www.hindawi.com

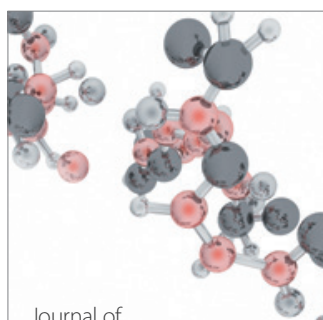

Analytical Methods

in Chemistry

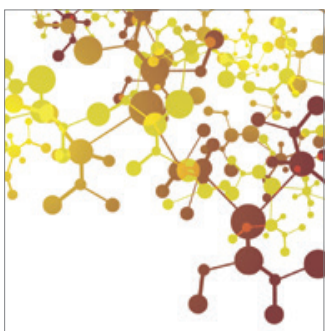

Journal of

Applied Chemistry

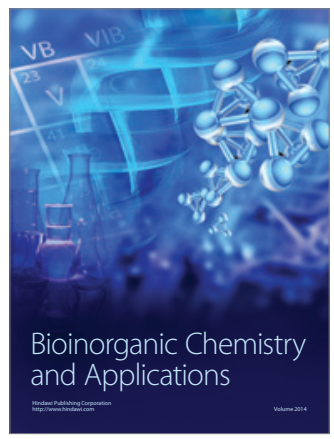

Inorganic Chemistry
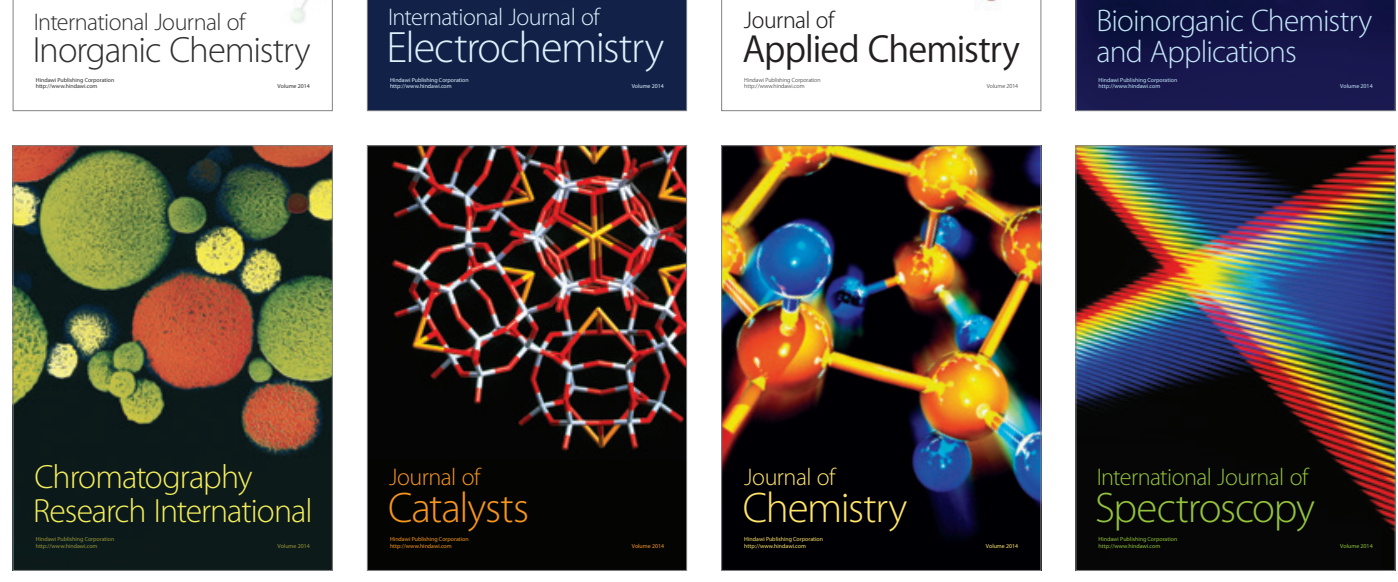